\title{
VICTIMIZACIÓN JUDICIAL, UNA MIRADA A LA ATENCIÓN DEL SISTEMA JURÍDICO A VÍCTIMAS QUE INTERPONEN LA DENUNCIA*
}

\author{
Juridical victimization, a view for the juristic system attention to \\ victims that interpose a complaint
}

Saida Lastenia Mantilla Ojeda**

Bertha Lucía Avendaño-Prieto***

Recepción: 25 de septiembre de 2019. Aceptación: 21 de junio de 2020

DOI: http://dx.doi.org/10.21017/Rev.Repub.2020.v29.a87

\section{RESUMEN}

Se propuso una definición para el trato inadecuado que reciben algunas víctimas por parte del sistema jurídico representado en sus operadores judiciales; así mismo, se realizó un estudio de tipo cualitativo de casos múltiples con el fin de analizar la experiencia vivida por 18 víctimas de violencia que interpusieron la denuncia. Para la recolección de información se utilizó una entrevista estructurada, la cual fue validada por 11 expertos, y se estableció el acuerdo con el índice $r_{W G}$. El estudio de las respuestas se hizo mediante un análisis de contenido deductivo. Los participantes reportan sentir miedo, frustración, intimidación, ansiedad, tristeza, incomodidad e irrespeto; adicionalmente, indican que los operadores judiciales muestran rechazo, insensibilidad, indiferencia, hostilidad y duda sobre el relato de la víctima, y al rendir el testimonio de los hechos consideran que hay ausencia de garantías de privacidad. Se presenta una definición de Victimización Judicial; los hallazgos indican, en términos generales, un resultado negativo desde la perspectiva de las víctimas.

* Artículo inédito, producto intelectual de las autoras, el cual hace parte de una tesis doctoral, inscrita en las líneas de investigación de psicología jurídica y criminológica y métodos de investigación aplicados a las ciencias del comportamiento. Proyecto de investigación: primer estudio derivado de la tesis de doctorado, el cual se ejecutó en un periodo de 18 meses. Universidad Católica de Colombia. Bogotá, D. C.

** Magíster en Psicología Jurídica. Magíster en Psicología. (c) a Ph. D. en Psicología. Docente, perito privado. Correo electrónico: slmantilla12@ucatolica.edu.co

*** Psicóloga Ph. D. Docente e investigadora. Universidad Católica de Colombia. Bogotá, D. C. Colombia. Correo electrónico: blavendano@ucatolica.edu.co 
a víctimas que interponen la denuncia

Palabras clave: (05.08.29) debido proceso, (03.01.55) denuncias, (03.05.55) víctima, (03.04.43) victimización (fuente: Tesauro de política criminal latinoamericana - ILANUD). Victimización judicial.

\begin{abstract}
A definition for the successful treatment that some victims received from the legal system in their judicial operators was proposed; moreover, a qualitative type study of multiple cases was realized in order to analyze the experience lived by 18 victims of violence who filed the complaint. For the collection of information a interview was structured, which was validated by 11 experts, the agreement with the $r_{W G}$ index was established. The study of the answers was performed by the analysis of deductive content. Participants report feeling fear, frustration, intimidation, anxiety, sadness, discomfort and disrespect; additionally, indicate that the judicial operators indicated rejection, insensitivity, indifference, hostility and doubt about the victim's story, and when giving testimony of the facts considerations that there is absence of privacy guarantees. A definition of Judicial Victimization is presented, the findings indicated in general terms, a negative result from the perspective of the victims.
\end{abstract}

Keywords: (05.08.29) due process, (03.01.55) complaints, (03.05.55) victim, (03.04.43) victimization (source: Latin American criminal policy thesaurus ILANUD). Judicial victimization.

La World Health Organization [WHO] (2002) en el informe mundial sobre la violencia y la salud entiende la violencia como "el uso deliberado de la fuerza física o el poder, ya sea en grado de amenaza o efectivo, contra uno mismo, otra persona o un grupo o comunidad, que cause o tenga muchas probabilidades de causar lesiones, muerte, daños psicológicos, trastornos del desarrollo o privaciones. Esta definición también abarca la violencia interpersonal, el comportamiento suicida y los conflictos armados. Cubre también una amplia gama de actos que van más allá del acto físico como las amenazas e intimidaciones, la muerte, las lesiones y las consecuencias del comportamiento violento" (p. 5).

De acuerdo con la normatividad colombiana, Congreso de Colombia, Ley 294 de 1996, art. 3, seriales b y c, «toda forma de violencia [...] se considera destructiva de su armonía y unidad, y por lo tanto, será prevenida, corregida y sancionada por las autoridades públicas; la oportuna y eficaz protección especial a aquellas personas [...] que sean o puedan llegar a ser víctimas, en cualquier forma, de daño físico o síquico, amenaza, maltrato, agravio, ofensa, tortura o ultraje [...]». También se considera violencia todo acto delincuencial 
que atente contra el bien jurídico tutelado por la ley, transgreda la normatividad, viole las garantías constitucionales y los derechos de quienes residen en el territorio colombiano (Congreso de Colombia, Código Penal Colombiano [CP], Ley 599, 2000; Constitución Política de Colombia [CPC] 1991; Congreso de Colombia, Sistema Penal Oral Acusatorio [SPOA], Ley 906, 2004).

La violencia es un fenómeno mundial que afecta diferentes poblaciones o víctimas, que son definidas por la Organización de las Naciones Unidas [ONU], en la Resolución 40/34 (1985), como las personas que "individual o colectivamente han sufrido daños, inclusive lesiones físicas o mentales, sufrimiento emocional, pérdida financiera o menoscabo substancial de sus derechos fundamentales, como consecuencia de acciones u omisiones que violen la legislación penal vigente en los Estados miembros, incluida la que proscribe el abuso de poder" (p. 12).

Beristaín (1999) distingue tres clases de victimización: primaria, que se deriva directamente del crimen; secundaria, que hace referencia a los sufrimientos que a las víctimas testigos y a los individuos pasivos de un delito, les infieren las instituciones encargadas de hacer justicia: policías, jueces, peritos, criminólogos, psicólogos, etc., y terciaria, que procede principalmente de la conducta posterior de la víctima y emerge de la victimización primaria y secundaria.

Echeburúa, et al. (2002) reconocen dos tipos de victimización: primaria, que se deriva directamente del hecho delictivo, y secundaria, resultado de la relación posterior establecida entre la víctima y el sistema jurídico-penal. Esta relación se presenta cuando la víctima interpone la denuncia del hecho delictivo del cual fue objeto. «La denuncia en materia penal es una manifestación de conocimiento mediante la cual una persona, ofendida o no con la infracción, pone en conocimiento del órgano de investigación un hecho delictivo, con expresión detallada de las circunstancias de tiempo modo y lugar, que le consten» (Corte Constitucional Sentencia, C1177/05).

Gutiérrez, et al. (2009) realizaron una revisión teórica del concepto de victimización secundaria y encontraron distintas denominaciones para el mismo término: victimización criminal, desviación, deriva, revictimización y doble victimización. La revictimización se refiere a múltiples victimizaciones, como el caso en que un individuo es víctima de violencia interpersonal en dos o más momentos de la vida; estas experiencias están separadas por el tiempo, y realizadas al menos por dos perpetradores diferentes (Rivera-Rivera, et al., 2006). Mientras que la doble victimización o victimización secundaria hace alusión a los sufrimientos que a las víctimas les infieren las instituciones encargadas de hacer justicia (Beristaín, 1999). 
Aranda, et al. (2014, p. 13) afirman que «La segunda victimización tiene lugar durante el proceso que se inicia desde la visita al centro de salud con motivo de la agresión sufrida, y puede prolongarse a lo largo de la interacción con la policía y el procedimiento legal. Se trata de un sentimiento negativo que aparece ligado a la repetición de la información emocionalmente dolorosa, la falta de empatía y sensibilidad del personal, así como la desinformación y el incumplimiento de expectativas judiciales».

El Fondo de Población de Naciones Unidas (UNFPA, 2013) la define como una segunda experiencia victimal que resulta algunas veces siendo más negativa que la primera, y puede llevar a incrementar el daño causado por el delito con otros de dimensión psicológica o patrimonial. De modo semejante, Soria y Sáiz (2006, p. 256) enuncian que la victimización secundaria se deriva de las relaciones de la víctima con las instituciones sociales (servicios sociales, sanitarios, medios de comunicación, jurídicos, etc.).

La OMS (2004) señala que la persona que en calidad de víctima acude a denunciar puede encontrar una actitud indiferente y un trato insensible frente al sufrimiento que padece. Este hecho particular se da de manera marcada durante la etapa de denuncia, según lo plantea Save The Children Alliance (2008), y durante la valoración médica (UNFPA, 2013).

Entre las causas de la victimización secundaria, se encuentra la incapacidad de las dependencias judiciales de comprender a las personas que atiende (Carbó, 2017), la asignación de funciones a personas que no cuentan con el perfil profesional para la orientación y asistencia a víctimas, y la ausencia de políticas públicas frente a la atención de víctimas (UNFPA, 2013).

Bodelón (2014) indica que la victimización secundaria es consecuencia de las inadecuadas prácticas de las instituciones. Larrauri (2003) propone que el desinterés, la desconsideración y la falta de cuidado y protección hacia las víctimas se derivan de los comportamientos estereotipados hacia estas.

Cubells, et al. (2010) añaden que, en la mayoría de los casos reportados por algún tipo de violencia, la actitud de los jueces suele ser negativa, lo que contribuye al incremento de la victimización secundaria. Además, las instalaciones donde se reciben la denuncias generalmente son inadecuadas para atenderlas (Vásquez, 2003; Volnovich, 2008). La evidencia empírica ha demostrado que algunos operadores judiciales, entre quienes se encuentran psicólogos, abogados y trabajadores sociales (Tapias, et al., 2013), en el ejercicio de su labor profesional despliegan un trato injusto, descortés (Wemmers, 2013), a quienes denuncian, generando nuevamente victimización. 
El paso por estos organismos supone un desgaste físico y psicológico que genera secuelas, puesto que la víctima debe declarar y revivir repetidamente la experiencia padecida (Aranda, et al., 2014). Para Orth (2002) trae como consecuencia la pérdida de confianza en el sistema legal por parte de la víctima. El relato de los procesos de victimización es un acto traumatizante, por la dilatación del proceso y la falta de información pertinente que llega a propiciar la victimización secundaria en la intervención judicial. Fernández y Vázquez (2014) plantean que la insatisfacción en los tribunales penales con el sistema de justicia parece haberse convertido en una constante que poco a poco se ha ido normalizando. Las diversas definiciones y usos del término «victimización secundaria» indican imprecisión en el constructo y llevan a analizar su pertinencia.

\section{MARCO LEGAL}

En relación con este tipo de victimización, a nivel internacional se identifican dos tipos de justicia que para el caso de Colombia también se reconocen: la justicia interaccional y la justicia procedimental, abordadas también por la psicología social y la psicología de las organizaciones (Greenberg \& Cropanzano, 2001; Vardi \& Weitz, 2004). La justicia interaccional aduce al trato digno y respetuoso que reciben las personas (sobre cómo perciben la atención recibida) y a la información que se les brindó en relación con el procedimiento que los afectaba (Greenberg \& Cropanzano, 2001; Omar, 2006). La justicia procedimental se refiere al debido proceso (Congreso de Colombia, CPC, 1991, art. 29) que se debe garantizar a las personas cuando acceden a la administración de justicia (CPC, 1991 art. 229); de esta forma, el Congreso de Colombia en la Ley 1719 (2014) adopta medidas para garantizar el acceso a la justicia de las víctimas.

En respuesta al fenómeno de la victimización judicial, diversas leyes internacionales y nacionales se han promulgado. "El Reglamento de la Unión Europea [UE] (606/2013), del Parlamento Europeo y del Consejo establece medidas de protección a las personas que tienen en riesgo su vida, su integridad física o psíquica, su libertad personal, su seguridad o su integridad sexual; además, exhorta a las autoridades a impedir cualquier forma de violencia [...]; este reglamento se aplica a todas las víctimas [...]. La Directiva 2012/29/UE del Parlamento Europeo y del Consejo, de 25 de octubre de 2012, establece normas mínimas sobre los derechos, el apoyo y la protección de las víctimas de delitos; garantiza que las víctimas reciban información y apoyo adecuados desde el primer contacto con las autoridades competentes y sus derechos cuando interponen una denuncia: derecho a recibir información acerca de su proceso, acceso a los servicios, apoyo a las víctimas, ser oído, no sufrir una victimización secundaria [...]" (UE, (606/2013); Redondo \& Garrido, 2013). 
a víctimas que interponen la denuncia

En Colombia, diferentes leyes han sido decretadas con el objetivo de garantizar el debido proceso y el acceso a la administración de justicia de las víctimas afectadas por algún tipo de delito, que acuden al aparato jurídico en busca del restablecimiento de sus derechos humanos. El Congreso de Colombia adopta medidas para garantizar el acceso a la justicia de las víctimas de diferentes tipos de delitos y establece mecanismos y herramientas para brindar asistencia, atención y reparación a las víctimas (Ley 1719/2014, y Decreto 4800/2011 que reglamenta la Ley 1448/2011).

La Corte Constitucional de Colombia en Sentencia T-735/17 “[...] señala que el Estado puede convertirse en un segundo agresor cuando no es diligente en atender las denuncias de violencia [...] y afirma que las autoridades [...] incurren en violencia institucional cuando por su acción u omisión les causan daño psicológico". En este orden de ideas se consideró necesario indagar acerca de la atención recibida desde el momento en que las víctimas interponen la denuncia.

Bajo los parámetros expuestos en el presente documento, se plantearon los siguientes objetivos: ofrecer una definición del constructo de victimización judicial (VJ); determinar la evidencia de validez de contenido del guion de una entrevista, a través del juicio de 11 expertos en atención a víctimas, entre quienes se encuentran dos psicólogos jurídicos, un psicólogo clínico, un psicómetra, dos abogados, dos médicos, un trabajador social y dos policías; y establecer si existe o no, victimización judicial, a través del análisis de contenido de la entrevista.

\section{MÉTODO}

Se realizó un diseño cualitativo fenomenológico de casos múltiples (Pérez, et al., 2017); las respuestas obtenidas fueron examinadas mediante un análisis de contenido deductivo, cuyo objetivo fue interpretar o comprender un fenómeno social a partir de las posturas de las personas.

La muestra estuvo conformada por 18 participantes, 17 mujeres y un hombre, entre quienes se encuentran cinco víctimas de violencia sexual y desplazamiento, cuatro víctimas indirectas de homicidio, dos de violencia doméstica y siete de desplazamiento forzoso, quienes denunciaron ante el sistema jurídico el delito del cual fueron víctimas y accedieron voluntariamente a responder la entrevista. El criterio de inclusión para la selección de los participantes era que hubieran sido víctimas de violencia sin importar el tipo de delito; el muestreo fue no probabilístico por conveniencia (Otzen \& Manterola, 2017). 
Guion de entrevista estructurada sobre la atención que reciben las víctimas que interponen una denuncia. Se diseñó un guion de entrevista estructurada (Díaz, et al., 2013) para indagar sobre tópicos relacionados con la atención, la interacción, las instalaciones, las respuestas y los procedimientos del aparato jurídico y los operadores judiciales con el denunciante, el cual se validó con 11 expertos que evaluaron y aprobaron la estructura del instrumento. Se analizó la pertinencia, la relevancia y la semántica de cada pregunta con el índice de acuerdo entre jueces $r_{W G}$. Luego de realizar los ajustes sugeridos por los evaluadores, se aplicó la entrevista a los participantes de manera estructurada y enfocada, en orden estricto y sin adición o eliminación de preguntas.

\section{Guion de entrevista}

La entrevista fue diseñada para víctimas de violencia que interponen la denuncia; el instrumento consta de 22 ítems, los cuales se encuentran distribuidos en tres ejes de indagación: violencia, actitud y victimización judicial. El primer eje de indagación (Violencia) abarca los ítems 1 al 8 y hace referencia al delito y a la atención que recibió por parte de los operadores judiciales. El segundo eje de indagación (Actitud) comprende desde el ítem 9 al 19, los cuales aluden a las actitudes -bien sea en un lenguaje verbal y/o no verbal- de los operadores judiciales desde la percepción de las víctimas. El tercer eje (Victimización judicial) abarca los ítems 20 al 22 e indaga sobre las consecuencias derivadas de la denuncia.

\section{Procedimiento}

La investigación se desarrolló en cinco fases. En la primera se efectuó una revisión bibliográfica sobre victimización judicial y diferentes constructos relacionados, los cuales permitieron definir la VJ y elaborar el guion de entrevista estructurada. En la segunda fase se elaboró el guion de la entrevista. En la tercera se estableció la evidencia de validez de contenido. En la cuarta se realizó el trabajo de campo y se aplicaron las entrevistas estructuradas en las instituciones previamente seleccionadas (Unidad de Víctimas y Casa de Justicia); paralelamente se organizaron los datos y se codificaron de forma tal que las entrevistas fueran suficientes para lograr una saturación teórica (Hernández, 2014). Finalmente, en la quinta fase se analizó la información recolectada mediante un análisis de contenido deductivo (Guix, 2008) con el software Atlas ti, versión 8 .

La presente investigación se ajustó a la legislación colombiana (Congreso de Colombia, Resolución 8430, 1993), la cual dicta las normas científicas, técnicas y administrativas para la investigación en salud en el país y clasifica los estudios de tipo encuesta sin manipulación de la conducta, como investigaciones 
sin riesgo o de riesgo mínimo para los participantes. También se ciñe a la práctica de investigaciones en psicología en Colombia (Congreso de Colombia, Ley 1090, 2006) con los parámetros éticos que garantizan la integridad y la seguridad de los participantes en una investigación.

\section{RESULTADOS}

Para alcanzar el primer objetivo propuesto, se revisaron las diferentes expresiones, no necesariamente sinónimas, utilizadas para analizar la victimización secundaria, lo cual indicó imprecisión en el constructo. El término Victimización Judicial se refiere específicamente al trato inadecuado que reciben algunas víctimas por parte del sistema judicial, representado en sus operadores judiciales, desde el momento en que la víctima entra en contacto con el sistema legal, instaura la denuncia y se vincula al proceso, hasta el esclarecimiento de los hechos, en un contexto o instancias netamente legales, que no incluye instituciones sociales, sanitarias ni medios de comunicación.

Al hacer alusión a la dinámica víctima-operador judicial, es acertado hablar de VJ, puesto que esta no solo se produce en la denuncia, sino también durante el proceso, la información requerida del proceso, o cuando se le solicita comparecer en presencia del victimario. Hechos que se desarrollan en contextos legales en los cuales se acciona la norma jurídica instaurada en la Constitución Política, el Código Penal y el Código de Procedimiento Penal, entre otras leyes promulgadas, las cuales procuran garantizar, restablecer y mantener los derechos de las víctimas.

La VJ surge de la dinámica de la víctima como usuaria del sistema legal y de la inadecuada praxis (atención, información, organización) del operador judicial; la VJ relaciona a la víctima del delito y los tipos de victimización a los cuales está expuesta en la diligencia que exhibe el operador en la atención y asistencia a la misma.

Después de la propuesta del término VJ se realizó el guion de entrevista, el cual fue sometido al análisis de los expertos, quienes evaluaron la pertinencia, la relevancia y la semántica de los ítems de la misma y eliminaron cuatro preguntas, incluyeron otras cuatro y modificaron 16. Para establecer el acuerdo entre jueces se utilizó el índice $r_{W G}$, puntajes superiores a .80 indican acuerdo (Wagner, Rau \& Lindemann, 2010). De los 78 índices calculados para las 22 preguntas en los tres criterios, solo en siete no hubo acuerdo. La tabla 1 presenta los índices de armonía interjueces de las preguntas que finalmente conformaron el instrumento. 
Tabla 1. Índices de armonía interjueces y observaciones realizadas a la entrevista

\begin{tabular}{|c|c|c|c|}
\hline Pregunta & Pertinencia & Relevancia & Semántica \\
\hline $\begin{array}{l}\text { 1. ¿Desde el momento que interpuso la denuncia cuánto tiempo } \\
\text { esperó para ser atendido(a)? }\end{array}$ & 0,978 & 0,978 & 0,890 \\
\hline $\begin{array}{l}\text { 2. ¿Cómo fue atendido(a) por las personas con las que se relacionó } \\
\text { al interponer la denuncia? }\end{array}$ & 0,978 & 0,978 & 0,838 \\
\hline 3. ¿Le prestaron atención? & 0,978 & 0,978 & 0,890 \\
\hline 4. ¿Se sintió escuchado(a)? & 1,000 & 1,000 & 0,978 \\
\hline 5. ¿La persona que lo(a) atendió realizó comentarios? & 0,978 & 0,898 & 0,890 \\
\hline 6. ¿Le solicitaron precisar su declaración? & 0,978 & 0,978 & 0,890 \\
\hline $\begin{array}{l}\text { 7. Señor(a): ¿Usted conoce el procedimiento para interponer una } \\
\text { denuncia por el delito del cual usted fue víctima? Si responde no, } \\
\text { pase a la siguiente pregunta. Si responde sí, preguntarle: ¿Ahora } \\
\text { qué debe hacer? }\end{array}$ & 1,000 & 0,978 & 0,898 \\
\hline 8. ¿Qué opina de la atención recibida? & 1,000 & 1,000 & 1,000 \\
\hline $\begin{array}{l}\text { 9. ¿Cómo se sintió cuando comentó los hechos que lo(a) trajeron a } \\
\text { este lugar? ¿Por qué? }\end{array}$ & 0,978 & 0,978 & 0,910 \\
\hline $\begin{array}{l}\text { 10. ¿Tuvo que desplazarse a diferentes lugares para ser } \\
\text { atendido(a)? }\end{array}$ & 1,000 & 1,000 & 1,000 \\
\hline 11. ¿Encontró respuesta a su denuncia? & 1,000 & 0,978 & 0,898 \\
\hline $\begin{array}{l}\text { 12. ¿Siente confianza en esta institución para que atienda su } \\
\text { denuncia? }\end{array}$ & 0,978 & 1,000 & 1,000 \\
\hline 13. ¿Siente que la persona que lo(a) atendió le creyó? & 0,978 & 1,000 & 0,978 \\
\hline 14. ¿La persona que lo(a) atendió le generó confianza? & 1,000 & 1,000 & 0,978 \\
\hline $\begin{array}{l}\text { 15. ¿Cómo le pareció el tono de voz utilizado por la persona que } \\
\text { lo(a) atendió? }\end{array}$ & 0,978 & 1,000 & 0,978 \\
\hline 16. ¿La persona que lo(a) atendió mostró interés en su caso? & 1,000 & 1,000 & 0,978 \\
\hline 17. ¿Le explicaron cuáles son sus derechos? & 1,000 & 1,000 & 0,978 \\
\hline 18. ¿La persona que lo(a) atendió le indicó lo que debía hacer? & 1,000 & 1,000 & 0,910 \\
\hline 19. ¿Usted entendió lo que debía hacer? & 1,000 & 1,000 & 0,898 \\
\hline 20. ¿A quiénes les contó lo que le sucedió? ¿Por qué? & 0,978 & 0,978 & 0,960 \\
\hline 21. ¿El sitio donde realizó su denuncia le garantizó privacidad? & 1,000 & 1,000 & 1,000 \\
\hline $\begin{array}{l}\text { 22. ¿En algún momento se sintió incómodo(a) durante la atención } \\
\text { brindada? ¿Por qué? }\end{array}$ & 1,000 & 1,000 & 1,000 \\
\hline
\end{tabular}


a víctimas que interponen la denuncia

En términos generales, las observaciones realizadas hicieron referencia a la repetición de preguntas y aspectos de redacción.

\section{Análisis de contenido de las entrevistas estructuradas}

Con base en las diferentes respuestas dadas por las víctimas, se realizó un análisis de contenido deductivo (Fernández, 2002). Se aplicaron, transcribieron y codificaron las entrevistas, para determinar las categorías. Posteriormente se revisaron los códigos, previo a la formación de las familias, para depurar y lograr saturación. Se empleó la codificación axial, en la cual las categorías que se relacionaron con dos o más observaciones se vincularon para formar las supracategorías o categorías axiales (Saldaña, 2009). Finalmente, se depuraron las categorías con una o más categorías axiales, para llegar a los núcleos que articularon el sistema categorial. A partir de la depuración se obtuvieron dos familias (Sandoval, 1996): Actitud, entendida como las tendencias adquiridas y relativamente duraderas para evaluar de un modo determinado un objeto, una persona, un suceso o una situación (Coll, et al., 1994), la cual presenta tres supracategorías: cognitiva, afectiva y conductual; y la familia Acceso a la administración de justicia, que consiste en el derecho que toda persona tiene de acudir al aparato jurídico cuando ha sido objeto de algún delito (Constitución Política de Colombia [CPC], 1991, art. 229; Congreso de Colombia, Ley 1719, 2014), la cual conlleva la supracategoría debido proceso (CPC,1991, art. 29), constructo relacionado con los tipos de justicia: procedimental, informacional e interaccional interpersonal- (Omar, 2006). Los códigos de las supracategorías se presentan en la tabla 2.

Tabla 2. Códigos de las supracategorías de las familias Actitud y Acceso a la administración de justicia

\begin{tabular}{|c|c|c|c|}
\hline 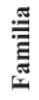 & Categoría & Supracategoría & Códigos (Respuestas dadas por los entrevistados) \\
\hline \multirow{4}{*}{ 密 } & \multirow{2}{*}{ 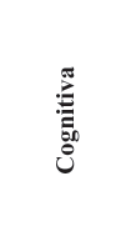 } & $\begin{array}{l}\text { Credibilidad hacia } \\
\text { las víctimas. }\end{array}$ & $\begin{array}{l}\text { Poca interacción. Indiferencia. Politización de la entidad. (14 } \\
\text { participantes percibieron poca credibilidad por parte del operador } \\
\text { judicial). }\end{array}$ \\
\hline & & $\begin{array}{l}\text { Satisfacción con la } \\
\text { atención recibida. }\end{array}$ & $\begin{array}{l}\text { Insatisfacción con la atención recibida ( } 9 \text { participantes). Atención } \\
\text { medianamente buena ( } 6 \text { participantes). Inconformes por no haber } \\
\text { recibido respuesta ( } 3 \text { participantes). }\end{array}$ \\
\hline & \multirow{2}{*}{ 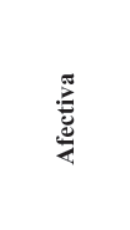 } & $\begin{array}{l}\text { Emociones sentidas } \\
\text { durante la atención. }\end{array}$ & $\begin{array}{l}\text { Miedo. Frustración. Resignación. Intimidación. Ansiedad. Tristeza. } \\
\text { Incomodidad. Retraumatización -tener que volver a recordar lo } \\
\text { sucedido- (13 participantes). Gratitud. Esperanza y tranquilidad ( } 5 \\
\text { participantes). }\end{array}$ \\
\hline & & $\begin{array}{l}\text { Empatía del } \\
\text { funcionario. }\end{array}$ & $\begin{array}{l}\text { Interés por el estado emocional de la víctima ( } 5 \text { participantes). } \\
\text { Desinterés ( } 13 \text { participantes). }\end{array}$ \\
\hline
\end{tabular}




\section{Continuación Tabla 2.}

\begin{tabular}{|c|c|c|c|}
\hline & \multirow{2}{*}{ ن⿺辶大 } & \multirow{2}{*}{$\begin{array}{l}\text { Percepción del trato } \\
\text { de los funcionarios. } \\
\begin{array}{l}\text { Lenguaje - verbal y } \\
\text { no verbal-del } \\
\text { funcionario. }\end{array}\end{array}$} & \multirow{2}{*}{$\begin{array}{l}\text { Conforme (con la atención del personero; percepción de mejoría e } \\
\text { interés [4 participantes]). Inconforme (ofrecimiento de ayuda no } \\
\text { recibida, indiferencia, funcionarios ocupados, irrespeto, } \\
\text { discriminación, instan a que la víctima busque trabajo [14 } \\
\text { participantes]). }\end{array}$} \\
\hline & & & \\
\hline \multirow{11}{*}{ 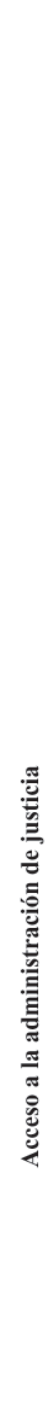 } & \multirow{8}{*}{ 䒿 } & $\begin{array}{l}\text { Dilatación de } \\
\text { atención y } \\
\text { respuesta. }\end{array}$ & $\begin{array}{l}\text { Atención: de una a cuatro horas ( } 9 \text { participantes). De uno a tres meses } \\
\text { ( } 9 \text { participantes). Respuesta inmediata ( } 3 \text { participantes). De uno a tres } \\
\text { meses ( } 5 \text { participantes). Hasta tres años ( } 5 \text { participantes). Hasta } 17 \text { años } \\
\text { ( } 5 \text { participantes). }\end{array}$ \\
\hline & & $\begin{array}{l}\text { Garantía de } \\
\text { privacidad. }\end{array}$ & $\begin{array}{l}\text { No garantía de privacidad. Servicio saturado (16 participantes). } \\
\text { Garantía de privacidad ( } 2 \text { participantes). }\end{array}$ \\
\hline & & $\begin{array}{l}\text { Completitud de la } \\
\text { atención. }\end{array}$ & $\begin{array}{l}\text { Sin profundización. Atención corta y rutinaria. Atención sistemática y } \\
\text { poco profunda ( } 15 \text { participantes). Atención detallada ( } 3 \text { participantes). }\end{array}$ \\
\hline & & Anotación fiel. & $\begin{array}{l}\text { Relato adecuado ( } 8 \text { participantes). No confirmación del relato con la } \\
\text { víctima ( } 10 \text { participantes). }\end{array}$ \\
\hline & & $\begin{array}{l}\text { Respuesta a la } \\
\text { denuncia. }\end{array}$ & $\begin{array}{l}\text { Respuesta obtenida (sí: } 6 \text { participantes; no: } 12 \text { participantes). Atención } \\
\text { diferencial (sí: } 2 \text { participantes; no: } 16 \text { participantes). En espera de } \\
\text { respuesta (sí: } 12 \text { participantes; no: } 6 \text { participantes). Indiferencia en la } \\
\text { atención (sí: } 12 \text { participantes; no: } 6 \text { participantes). Inconformidad con } \\
\text { la respuesta recibida (sí: } 7 \text { participantes; no: } 11 \text { participantes). } \\
\text { Respuesta demorada (sí: } 14 \text { participantes; no: } 4 \text { participantes). }\end{array}$ \\
\hline & & $\begin{array}{l}\text { Operadores } \\
\text { judiciales. }\end{array}$ & $\begin{array}{l}\text { Personero -conoce el direccionamiento a víctimas- (sí: } 15 \\
\text { participantes; no: } 3 \text { participantes). Abogado. Trabajador social. } \\
\text { Diversos operadores judiciales -no conocen ; no precisan el } \\
\text { direccionamiento a víctimas-(sí: } 5 \text { participantes; no: } 13 \text { participantes). }\end{array}$ \\
\hline & & Hecho victimizante. & $\begin{array}{l}\text { Tipos de delito ( } 2 \text { víctimas de violencia intrafamiliar; } 4 \text { víctimas } \\
\text { indirectas de homicidio y desplazamiento; } 5 \text { víctimas de violencia } \\
\text { sexual y desplazamiento; } 7 \text { víctimas de desplazamiento forzado). } \\
\text { Interés en la atención (solicitar ayuda humanitaria [ } 3 \text { participantes]; en } \\
\text { espera de indemnización [un participante]; ausencia de respuesta [11 } \\
\text { participantes]; reparación insuficiente [un participante]; ayuda } \\
\text { humanitaria e información de beneficios [ } 2 \text { participantes]). }\end{array}$ \\
\hline & & $\begin{array}{l}\text { Movilización para } \\
\text { la atención. }\end{array}$ & $\begin{array}{l}\text { No fue necesaria la movilización ( } 12 \text { participantes). Fue necesario } \\
\text { acudir a diferentes instancias ( } 6 \text { participantes). }\end{array}$ \\
\hline & \multirow{3}{*}{ ב⿱艹 } & $\begin{array}{l}\text { Explicación de } \\
\text { derechos. }\end{array}$ & $\begin{array}{l}\text { Tenía conocimiento sobre derechos del denunciante (4 participantes). } \\
\text { Desinformación sobre los derechos del denunciante ( } 14 \text { participantes). }\end{array}$ \\
\hline & & $\begin{array}{l}\text { Conocimiento del } \\
\text { procedimiento de la } \\
\text { denuncia. }\end{array}$ & $\begin{array}{l}\text { Tenía conocimiento de los procedimientos ( } 5 \text { participantes). } \\
\text { Desconocimiento de procedimientos ( } 13 \text { participantes). }\end{array}$ \\
\hline & & $\begin{array}{l}\text { Orientación de la } \\
\text { ruta. }\end{array}$ & $\begin{array}{l}\text { Tenía conocimiento de la ruta ( } 4 \text { participantes). Desinformación sobre } \\
\text { la ruta ( } 14 \text { participantes). }\end{array}$ \\
\hline
\end{tabular}


Continuación Tabla 2.

\begin{tabular}{|l|l|l|}
\hline \multirow{5}{*}{} & $\begin{array}{l}\text { Comodidad en la } \\
\text { institución. }\end{array}$ & $\begin{array}{l}\text { Comodidad en la entidad (6 participantes). Incomodidad y } \\
\text { retraumatización (12 participantes). }\end{array}$ \\
\cline { 2 - 3 } & $\begin{array}{l}\text { Confianza hacia la } \\
\text { institución. }\end{array}$ & $\begin{array}{l}\text { Confianza en la entidad (8 participantes). Desconfianza en la entidad, } \\
\text { lentitud en el proceso (10 participantes). }\end{array}$ \\
\cline { 2 - 3 } & $\begin{array}{l}\text { Percepción de la } \\
\text { escucha. }\end{array}$ & $\begin{array}{l}\text { Adecuada por parte del personero (8 participantes). Percepción de no } \\
\text { escucha -inadecuada; no permiten ahondar en el detalle; se rechaza } \\
\text { aclaraciones- (10 participantes). }\end{array}$ \\
\cline { 2 - 4 } & $\begin{array}{l}\text { Confianza hacia el } \\
\text { funcionario. }\end{array}$ & $\begin{array}{l}\text { Desconfianza hacia el funcionario -poca interacción. Apatía.- (11 } \\
\text { participantes). Confianza en el operador judicial (7 participantes). }\end{array}$ \\
\cline { 2 - 4 } & $\begin{array}{l}\text { Interés del } \\
\text { funcionario. }\end{array}$ & $\begin{array}{l}\text { Interés hacia la víctima. Comunicación con la víctima (6 participantes). } \\
\text { Desinterés por la víctima. Preguntas de rutina (12 participantes). }\end{array}$ \\
\hline
\end{tabular}

En la familia Actitud, supracategoría afectiva, categoría emoción durante la atención, los códigos se clasificaron en dos emociones, negativas y positivas: las negativas fueron miedo, frustración, resignación, intimidación, ansiedad, tristeza, incomodidad, victimización secundaria y desinterés del Estado por la víctima; las positivas fueron gratitud, esperanza y tranquilidad.

En la familia Acceso a la justicia se encuentran los tipos de justicia y las categorías que de estos se derivan. De las doce categorías identificadas, solo la anotación fiel, la movilización para atención y la percepción de la escucha fueron favorables. En la categoría dilatación de atención y respuesta, se encontraron opiniones a favor y en contra en igual proporción; en todas las demás, se infiere la valoración del trato que recibieron los denunciantes.

\section{DISCUSIÓN}

A través de la entrevista se alcanzó el objetivo propuesto. La revisión bibliográfica permitió inferir la imprecisión del término victimización secundaria, aspecto que llevó a proponer el constructo Victimización Judicial.

Los códigos de las categorías fueron consistentes con elementos que caracterizan la victimización secundaria (judicial), como la incredibilidad de los funcionarios, puesto que dudan del relato de las víctimas (Cubells, et al., 2010), insatisfacción con la atención recibida -supracategoría cognitiva- (Beristaín, 1999; Ojeda, 2015; OMS, 2004; Soria \& Sáiz, 2006; UNFPA, 2013), emoción tensión emocional- durante la atención (Orth, 2002; Soria \& Sánchez, 2009), falta de empatía del funcionario -supracategoría afectiva- (Aranda, et al., 2014; Laxminarayan, 2012) y percepción de las víctimas sobre el trato, lenguaje verbal 
y no verbal por parte del funcionario -supracategoría conductual- (Consejo General del Poder Judicial, 2011-2013; OMS, 2016).

Los hallazgos de las entrevistas concuerdan con los planteamientos de diferentes autores: actitud indiferente por parte del operador judicial (OMS, 2004), trato hostil (Beristaín 1999; Larrauri, 2003) y proceso inadecuado (Garrido, 1993).

De las doce categorías derivadas que dan cuenta de la valoración del trato que recibieron los denunciantes, se infiere VJ: falta privacidad, aspecto que se corroboró cuando se realizaron las entrevistas, puesto que la persona al tramitar la denuncia queda expuesta, ya que las instalaciones carecen de condiciones adecuadas para asegurar su privacidad, aspecto que refuerza la vulnerabilidad a la que se encuentra expuesta (Puerto, 2004; Vásquez, 2003; Volnovich, 2008).

Las víctimas manifestaron que solo el personero conoce su función; de hecho, varios autores afirman que la asignación de funciones se adjudica a personas que no cuentan con el perfil profesional necesario y adecuado para la atención y asistencia a víctimas (UNFPA, 2013). De las categorías hecho victimizante y explicación de derechos, se deduce que los participantes perciben desinformación sobre sus derechos y ausencia de respuesta, lo cual hace que las víctimas deban repetir lo sucedido ante distintos actores que, si bien pertenecen a diversas instituciones, conforman el mismo sistema del proceso penal (Puerto, 2004).

Sobre la categoría respuesta a la denuncia, las víctimas manifestaron no obtener respuesta, e inconformidad con la respuesta recibida; lo cual implica que la reparación es insuficiente y los organismos públicos y privados de atención y asistencia no propenden a la ayuda inmediata (humanitaria).

Las categorías conocimiento del procedimiento de la denuncia y orientación de la ruta indicaron que las víctimas perciben desconocimiento en el procedimiento y falta de información sobre la ruta que deben seguir, dos razones que desfavorecen el encuentro de las víctimas con el sistema jurídico; la información incompleta se traduce en el desgaste psico-emocional de las víctimas (Aranda, et al., 2014; Gutiérrez, et al., 2009).

Acerca de las categorías confianza hacia la institución y comodidad en la institución, las víctimas perciben incomodidad, retraumatización, desconfianza en la entidad y lentitud en el proceso, aspectos que propician miedo, frustración, intimidación, ansiedad, tristeza e incomodidad, que se traduce en angustia y temores (Soria, 1998). En otros casos, tensión, ansiedad y estrés 
(Soria \& Sánchez, 2009), aislamiento social, descontento, depresión (Ojeda, 2015).

Respecto de las categorías confianza hacia el funcionario e interés del funcionario, los participantes perciben poca interacción, apatía, desinterés y preguntas de rutina, que llevan a la pérdida de confianza en el sistema legal por parte de las víctimas (Orth, 2002).

Las categorías anotación fiel, movilización para atención y percepción de la escucha no se determinaron como desencadenantes de VJ, de acuerdo con lo reportado por los participantes. Se evidencia un mayor número de emociones negativas en comparación con las positivas frente a la denuncia, aspecto que corrobora los planteamientos de Aranda, et al. (2014), Ardaya e Iñiguez (2007), Mantilla (2015), y la OMS (2004).

En medio de tantas leyes promulgadas para proteger, asistir y ofrecer la atención adecuada a las víctimas, se evidencia inadecuada praxis en la atención a las mismas; más aún, cuando se constató al momento de realizar las entrevistas que las víctimas tienen que llegar al sitio donde interponen la denuncia entre tres y cuatro horas antes de recibir un turno para ser atendidas varias horas después. Razones que invitan a seguir investigando acerca de esta temática, de manera que los diversos escenarios judiciales y sus funcionarios reflexionen acerca de la importancia de humanizar el sistema desde la atención a víctimas (López, 2008), así como el papel que la justicia tiene como agente terapéutico (Wexler, 2014). Con el objetivo de contribuir en la disminución de la carga económica para los países, en atención sanitaria, vigilancia del cumplimiento de la ley y pérdida de productividad (OPS, OMS, UNODC \& UNDP, 2016).

Los hallazgos del presente estudio indican la necesidad de continuar promoviendo las buenas prácticas en atención y asistencia por parte de los operadores judiciales a víctimas de violencia, puesto que se evidenció la incapacidad de las dependencias judiciales para comprender a las personas que atienden (Carbó, 2017).

Es perentorio promulgar normas legales que investiguen y, de ser necesario, penalicen a los operadores judiciales que no accionan la adecuada praxis en la atención a víctimas; puesto que la aplicación de la norma jurídica tiene un impacto emocional en el bienestar psicológico de las víctimas (Winick, 2007).

En cuanto a las limitaciones encontradas en el presente estudio, se destaca el difícil acceso a la muestra y el tamaño de la misma, puesto que se halló prevención por parte de los participantes; además, solo se contó con la participación de un hombre. 


\section{REFERENCIAS}

Aranda López, M., Montes-Berges, B., Castillo-Mayén, M. R., \& Higueras, M. (2014). Percepción de la segunda victimización en violencia de género. Escritos de Psicología (Internet), 7(2), 11-18. ISSN 1989-3809 DOI: 10.5231/psy.writ.2014.1502

Ardaya, E. \& Iñiguez. (2007). Corte Suprema de Justicia, Tribunal Constitucional Bolivia, Sesgo de Género en la Administración de la Justicia. Recuperado el 21 noviembre de 2016 de www.cidh.org/women/ Acceso07/cap1.htm

Beristaín, A. (1999). Criminología y Victimología. En A. Beristain (Eds.). El nuevo código penal de 1995 desde la victimología (219-264). Bogotá, Colombia: Leyer.

Bodelón, E. (2014). Violencia institucional y violencia de género. En Anales de la Cátedra Francisco Suárez, 48, 131-155. Recuperado de: https://core.ac.uk/download/ pdf/132092557.pdf

Carbó, P. A. (2017). Abriendo puertas y ventanas a una perspectiva psicosocial feminista: Análisis sobre la violencia de género. Psicoperspectivas, 16(2), 79-90. Recuperado de: http:// dx.doi.org.ezproxy.unbosque.edu.co/10.5027/psicoperspectivasvol16-issue2-fulltext-1021.

Coll, C., Pozo, J., Sarabia, B. \& Valls, E. (1994). Los contenidos en la reforma: Enseñanza y aprendizaje de conceptos, procedimientos y actitudes. Madrid, España: Santillana.

Congreso de Colombia. (4 de octubre de 1993). Resolución 8430 de 1993. Por la cual se establecen las normas científicas, técnicas y administrativas para la investigación en salud. Bogotá: Ministerio de la Protección Social. Recuperado de: https:// www.minsalud.gov.co/sites/rid/Lists/BibliotecaDigital/RIDE/DE/DIJ/RESOLUCION-8430-DE-1993.PDF

Congreso de Colombia. (16 de julio de 1996). Ley 294. Diario Oficial, nro. 42.836, del 22 de julio de 1996. Título I, Objeto, Definición y Principios Generales. Recuperado de: https://www.icbf.gov.co/cargues/avance/docs/ley_0294_1996.htm

Congreso de Colombia. (24 de julio de 2000). Ley 599 de 2000, Código Penal. Libro primero, Parte general, título I, De las normas rectoras de la ley penal colombiana. Recuperado de: http://www.alcaldiabogota.gov.co/sisjur/normas/Norma1. jsp?i=6388

Congreso de Colombia. (31 de agosto de 2004). Ley 906, Diario Oficial, nro. 45.658, de septiembre 1 de 2004; del 1 de enero de 2005 entra a regir el Sistema Penal Acusatorio [SPOA]. Recuperado de: http:/ / www.alcaldiabogota.gov.co/sisjur/normas/ Norma1.jsp?i=14787 
Congreso de Colombia. (6 de septiembre de 2006). Ley del psicólogo. [Ley 1090 de 2006]. Recuperado de: http:/ / www.sociedadescientificas.com/userfiles/file/LEYES/1090\%2006.pdf

Congreso de Colombia. (10 de junio de 2011). Decreto 4800 de 2011 (reglamenta la [Ley 1448 de 2011]), reglamentada por el Decreto Nacional 3011 de 2013. Por el cual se dictaminan medidas de atención, asistencia y reparación integral a las víctimas del conflicto armado interno y se dictan otras disposiciones. Recuperado de: http:/ /www.unidadvictimas.gov.co/es/ley-1448-de-2011/136533

Congreso de Colombia. (18 junio de 2014). Ley 1719, Diario Oficial, nro. 49.186, del 18 de junio de 2014. Título I, Objeto, Definición y Principios Generales. Recuperado de: http://www.secretariasenado.gov.co/senado/basedoc/ley_1719_2014.html

Consejo General del Poder Judicial. (2011). Informe sobre víctimas mortales de la violencia de género y de la violencia doméstica en el ámbito de la pareja o ex pareja.

Consejo General del Poder Judicial. (2013). Guía de criterios de actuación judicial frente a la violencia de género. Recuperado el 16 de noviembre de 2016 de http:/ / www.mujeresenred.net/IMG/pdf/guia_criterios_actuacion_judicial.pdf

Constitución Política de Colombia [Const.].(1991). Artículo 29 [Título II, Capítulo I]. Disponible en: http://www.secretariasenado.gov.co/index.php/constitucion-politica

Constitución Política de Colombia [Const.].(1991). Artículo 229 [Título VIII, Capítulo I]. Disponible en: http://www.secretariasenado.gov.co/index.php/constitucionpolitica.

Corte Constitucional de Colombia. (Sentencia C-1177/05). Disponible en: http:// www.corteconstitucional.gov.co/relatoria/2005/C-1177-05.htm

Corte Constitucional de Colombia. (15 de diciembre de 2017). Sentencia T-735/17 [MP. Antonio Lizarazo]. Recuperado de: http://www.corteconstitucional.gov.co/ relatoria/2017/t-735-17.htm

Cubells, J., Calsamiglia, A. \& Albertín, P. (2010). El ejercicio profesional en el abordaje de la violencia de género en el ámbito jurídico-penal: un análisis psicosocial. Anales de psicología, 26(1), 369-377.

Díaz, L., Torruco, U., Martínez, M., \& Varela, M. (2013). La entrevista, recurso flexible y dinámico. Investigación en Educación Médica, 2(7), 162-167.

Echeburúa, E., Corral, P., \& Amor, P. J. (2002). Evaluación del daño psicológico en las víctimas de delitos violentos. Psicothema, 14(1), 139-146. Disponible en: https:// 
www.researchgate.net/profile/Enrique_Echeburua/publication/293913354_ Evaluacion_del_daño_psicológico_en_las_víctimas_de_delitos_violentos_1/ links/5b0dc6250f7e9b1ed701221a/evaluacion-del-dano-psicologico-en-lasvictimas-de-delitos-violentos-1.pdf

Fernández, F. (2002). El análisis de contenido como ayuda metodológica para la investigación. Revista de Ciencias Sociales (Cr), 2(96).

Fernández, E. \& Vázquez. (2014). Desarrollo y validación de una escala para medir la confianza en los tribunales. Recuperado de: http://www.indret.com/pdf/ 1059_es.pdf

Fondo de Población de Naciones Unidas [UNFPA]. (2013). Por una atención libre de victimización secundaria: en casos de la violencia sexual. Factores generadores de victimización secundaria por parte del operador de justicia. 43-44. El Salvador.

Garrido, E. (1993). La policía en la sociedad actual a la luz de la ley orgánica 2/ 86. Ciencia policial. 23, 65-81.

Greenberg, J. \& Cropanzano, R. (2001). Advances in organizational justice. Estados Unidos: Stanford University Press.

Guix, J. (2008). El análisis de contenidos: ¿Qué nos están diciendo? Revista de Calidad Asistencial, 23(1), 26-30. DOI: 10.1016/S1134-282X (08)70464-0

Gutiérrez de Piñeres, C., Coronel, E. \& Pérez, C. A. (2009). Revisión teórica del concepto de victimización secundaria. Liberabit, 15(1), 49-58. Recuperado en 19 de abril de 2018, de http:/ / www.scielo.org.pe/scielo.php?script=sci_arttext\&pid=S172948272009000100006\&lng=es\&tlng=es.

Hernández, R. (2014). La investigación cualitativa a través de entrevistas: su análisis mediante la teoría fundamentada. Cuestiones Pedagógicas, 23, 2014, 187-210. Recuperado de: http:/ /institucional.us.es/revistas/cuestiones/23/Mis_5.pdf

Larrauri, E. (2003). “Motius per entendre per qué algunes dones maltrac-tades retiren les denúncies". Fórum. La revista del Centre d’estudis jurídics i Formació especialitzada. Generalitat de Catalunya, núm. març 2, 24-29.

Laxminarayan, M. (2012). Procedural Justice and Psychological Effects of Criminal Proceedings: The Moderating Effect of Offense Type. Social Justice Research, 25(4): 390-405. DOI: 10.1007/s11211-012-0167-6

López, A. M. (2008). El Trabajo social forense y el enfoque de Justicia Terapéutica aplicado a los menores transgresores [Cd-rom]. Puerto Rico:(se). 
Mantilla S. (2015). La revictimización como causal del silencio de la víctima. Rev. cienc. Forenses Honduras, 1(2), 3-12. Recuperado de: http:/ / www.bvs.hn/RCFH/ pdf/2015/pdf/RCFH1-2-2015-4.pdf

Ojeda, S. (2015). Escala SAMANTO: Un Instrumento para medir la revictimización. Revista Skopein, 1(7).

Omar, A. (2006). Victimization, justice individualism-colectivism victimización, justicia individual y colectiva. México: Xalapa.

Organización de las Nacionales Unidas [ONU], Resolución 40/34 de (1985). Aplicación de la Declaración de los principios fundamentales de justicia para las víctimas de delitos y del abuso de poder. Tercera parte, Capítulo II. Víctimas, (3.b, c.): págs. 12, 316. Recuperado el 20 de octubre de 2016, de http:/ / www.osce.org

Organización Mundial de la Salud [OMS]. (2004). Intervenir en salud mental. Recuperado el 1 de noviembre de 2016, de http://www.who.int/mental_health/ advocacy/en/spanish_final.pdf

Organización Mundial de la Salud [OMS]. (2016). Violencia contra la mujer. Recuperado el 17 de noviembre de 2016, de http:/ / www.who.int/mediacentre/factsheets/ fs $239 /$ es/

Organización Panamericana de la Salud [OPS], Organización Mundial de la Salud [OMS], Oficina de las Naciones Unidas contra la Droga y el Delito [UNODC] \& Programa de las Naciones Unidas para el Desarrollo [UNDP-PNUD]. (2016). Informe sobre la situación mundial de la prevención de la violencia 2014. Recuperado de: https://oig.cepal.org/sites/default/files/informe_sobre_la_situacion_ mundial_de_la_prevencion_de_la_violencia.pdf

Orth, U. (2002). Secondary Victimization of Crime Victims by Criminal Proceedings. Alemania: Social Justice Research, 15(4), 313-325.

Otzen, T., \& Manterola, C. (2017). Técnicas de muestreo sobre una población a estudio. International Journal of Morphology, 35(1), 227-232. Recuperado de: https:// scielo.conicyt.cl/scielo.php?pid=S0717-95022017000100037\&script=sci_arttext

Pérez, R., Lagos, L., Mardones, R. \& Sáez, F. (2017). Diseños de investigación y muestreo cualitativo. Lo complejo de someter la flexibilidad del método emergente a una taxonomía apriorística. Investigação Qualitativa em Saúde (2), 1111- 1120. Recuperado de: https://www.researchgate.net/publication/319099821_Disenos_ de_investigacion_y_muestreo_cualitativo_Lo_complejo_de_someter_la_flexibilidad_del_metodo_emergente_a_una_taxonomia_aprioristica 
Puerto, M. (2004). Evaluación de la reforma procesal penal desde una perspectiva de género: Honduras, informe final. Recuperado el 23 de febrero de 2019 de https: / / www.cidh.oas.org/women/Acceso07/cap2.htm

Redondo, S., \& Garrido, V. (2013). Principios de criminología (4. ${ }^{\text {ta }}$ ed.), 879. Valencia. Tirant Lo Blanch.

Reglamento Unión Europea [UE]. (606/2013). Del Parlamento Europeo y del Consejo (12 de junio de 2013). Relativo al reconocimiento mutuo de medidas de protección en materia civil. Diario Oficial de la Unión Europea. Disponible en: https:/ / eurlex.europa.eu/legal-content/ES/TXT/PDF/?uri=CELEX:32013R0606\&from=EN

Rivera-Rivera, L., Allen, B., Chávez-Ayala, R., \& Ávila-Burgos, L. (2006). Abuso físico y sexual durante la niñez y revictimización de las mujeres mexicanas durante la edad adulta. Salud pública de México, 48, s268-s278. Recuperado de: https:/ / www.scielosp.org/article/spm/2006.v48supp12/s268-s278/

Saldaña, J. (2009). The Coding Manual for Qualitative Researchers. SAGE Publications Led: Londres.

Sandoval, C. (1996). Investigación cualitativa. Instituto Colombiano para el Fomento de la Educación Superior, Icfes.

Save the Children Alliance, ONG. (2008). Protocolo policial de atención inmediata a víctimas de trata de personas. San Salvador. Save the Children. Recuperado de http://violenciaytrata.savethechildren.es/docs/Docs/31/4.pdf

Soria, M. (1998). Psicología y Práctica Jurídica. España: Ed. Ariel. S. A.

Soria, M. \& Sáiz, D. (2006). Psicología criminal. Madrid: Pearson educación, S. A. Recuperado de: http://www.universidadcultural.com.mx/online/claroline/ backends / download.php?url=L1BzaWNvbG9naWFfQ3JpbWluYWwucG Rm\&cidReset $=$ true\&cidReq $=1 \_003$

Soria, M. \& Sánchez, J. (2009). El agresor sexual y la víctima. Madrid, España: Marcombo.

Tapias, Á. C., Sánchez, L. A., \& Torres, S. T. (2013). Reconocimiento de indicadores de alienación parental en operadores de justicia de Bogotá. Suma Psicológica, 20(1).

Vardi, Y.\& Weitz, E. (2004). Misbehavior in organizations: theory, research, and management. Estados Unidos: Lawrence Erlbaum.

Vásquez, B. (2003). Estudio de las secuelas postraumáticas. En: B. Vásquez (Eds.). Estudio de las secuelas postraumáticas en niños objeto de agresiones sexuales denunciadas (pp. 5-37). Madrid, España: Ed. Colegio Oficial de Psicólogos. 
Volnovich, J. (2008). Abuso sexual en la infancia. La revictimización (3. ${ }^{\mathrm{a}}$ ed.). Buenos Aires, Argentina: Lumen.

Wagner, S. M., Rau, C. \& Lindemann, E. (2010). Multiple Informant Methodology: A Critical Review and Recommendations, Sociological Methods \& Research, 38(4). 582-618. DOI: 10.1177/0049124110366231

Wemmers, J.-A. (2013). Victims' experiences in the criminal justice system and their recovery from crime. International Review of Victimology. 19(3), 221-233. DOI:10.1177/ 0269758013492755

Wexler, D. B. (2014). Justicia terapéutica: una visión general (Therapeutic Jurisprudence: An Orientation). Arizona Legal Studies Discussion Paper, (14-23).

Winick, B. (2007). Justicia terapéutica y los juzgados de resolución de problemas. University of Miami School of Law.

World Health Organization. (2002). Informe mundial sobre la violencia y la salud: resumen, pág. 5. Disponible en: https://apps.who.int/iris/bitstream/handle/10665/ 43431/9275324220_spa.pdf 